\title{
Unravelling Molecular Composition of Products from Cobalt Catalysed Fischer-Tropsch Reaction by Comprehensive Gas Chromatography: Methodology and Application
}

\author{
F. Bertoncini ${ }^{1}$, M.C. Marion ${ }^{2}$, N. Brodusch ${ }^{3}$ and S. Esnault ${ }^{3}$ \\ 1 Institut français du pétrole, IFP-Lyon, Direction Catalyse et Séparation, BP 3, 69390 Vernaison - France \\ 2 Institut français du pétrole, IFP-Lyon, Direction Conception Modélisation Procédés, BP 3, 69390 Vernaison - France \\ 3 Institut français du pétrole, IFP-Lyon, Direction Physique et Analyse, BP 3, 69390 Vernaison - France \\ e-mail: fabrice.bertoncini@ifp.fr - m-claire.marion@ifp.fr - nicolas.brodusch@ifp.fr - sebastien.esnaulł@ifp.fr
}

Résumé - Élucider la composition moléculaire des produits obtenus par la réaction de FischerTropsch catalysée par le cobalt par chromatographie gazeuse bidimensionnelle : méthodologie et application - De nouvelles approches analytiques combinant différents types de méthodes chromatographiques telles que les chromatographies en phase gazeuse de basse résolution, de haute résolution et bi-dimensionnelle ont été mises en oeuvre pour améliorer la caractérisation moléculaire des produits de synthèse Fischer-Tropsch (FT). Particulièrement, la composition détaillée des oléfines et des oxygénés a été obtenue grâce à la résolution améliorée et la grande capacité de séparation fournies par la GC-2D. Une telle description de la totalité des effluents de la réaction de Fischer-Tropsch apporte des informations additionnelles qui peuvent être mises à profit pour améliorer la connaissance de la réaction. Ainsi, nous avons montré que les trois familles de produits (paraffines, oléfines et oxygénés) présentent leur propre distribution Anderson Schulz Flory (ASF). En dehors du méthane et de l'éthylène, la sélectivité de la réaction de Fischer-Tropsch a pu être décrite par des coefficients de croissance de chaîne spécifiques à chaque famille. Ces résultats peuvent permettent une meilleure compréhension du mécanisme réactionnel. Une hypothèse est proposée.

\footnotetext{
Abstract - Unravelling Molecular Composition of Products from Cobalt Catalysed Fischer-Tropsch Reaction by Comprehensive Gas Chromatography: Methodology and Application - New analytical approaches combining different types of gas chromatography techniques such as low resolution, high resolution and two-dimensional gas chromatography were carried out to provide enhanced molecular characterization of Fischer-Tropsch (FT) products. In particular, a detailed composition of olefin and oxygenates by-products was achieved thanks to magnified resolution associated with the high peak capacity provided by $G C \times G C$. Such a detailed description of the whole FT products distribution brings additional information which improve the Fischer-Tropsch reaction knowledge.

Thus, we have shown that all the three products family (paraffin, olefin and oxygenates) present their own Anderson Schulz Flory (ASF) distribution. Apart from methane and ethylene which present their own particularity, the Fischer-Tropsch selectivity can be described by three chain growth coefficients relative to each products family. These results allow new understanding of the reaction mechanism. An hypothesis is proposed.
} 


\section{INTRODUCTION}

The Fischer-Tropsch (FT) synthesis is a surface catalyzed polymerisation process that use $\mathrm{CHx}$ monomers, formed by hydrogenation of adsorbed carbon monoxide $(\mathrm{CO})$, in order to produce hydrocarbons with a broad range of chain length and functionality. A huge interest has been brought to this reaction since the years 1990's, due to the new international energy context, the new environmental concern, the increasing demand for transportation fuels or oil prices increase. Thus, both academic research and process development works has been strengthened on the Fischer-Tropsch synthesis for gas to liquid process development (GTL) as well as for coal to liquid or biomass to liquid processes development (CTL and BTL, respectively).

Fischer-Tropsch catalyst selectivity has been then intensively studied with both cobalt $(\mathrm{Co})$ and iron $(\mathrm{Fe})$ catalysts. However Fischer-Tropsch reaction mechanism is still under discussion: the mathematical polymerization law reported in the past by Schulz and Flory, also called Anderson Schulz Flory (ASF) distribution is reported to present some deviation(s) in case of Fischer-Tropsch synthesis [1-4]. It is common to represent the chain length distribution of FT-products, on both $\mathrm{Co}$ and Fe based catalyst, by superposition of two ASF distributions, namely $\alpha_{1}$ and $\alpha_{2}$ [1] distributions. This superposition of two ASF distributions has been interpreted by two different mechanisms of chain growth whereas other authors consider that olefin-1 readsorption can be responsible for the product distribution deviation [1-4]. The ASF deviation has also been attributed to two growth factors at two different catalytic sites (dual sites) [5]. It is undoubted that olefin-1 re-adsorption is observed when olefin co-feeding is performed [3]. But the co-feeding peculiar environment has to be considered and it may not be entirely representative of regular synthesis condition [6], except when an internal recycle is in operation, which can be the case in industrial process conditions [7,8]. Thus, the discussion about the causes of deviations is still a subject of debate: we can mention for instance a quite original hypothesis published by Puskas et al. [6], showing a multiplicity of the chain growth probability. This hypothesis is supported by non constant kinetic environment consideration including various secondary reactions, fast direct reaction between reagent present in bubbles and slurry catalyst particles.

The molecular characterization of the FT main products and other sub-products appears therefore as a critical step towards an improved knowledge of the Fischer-Tropsch reaction. However, the conventional analytical methods for FT product fail to provide detailed molecular information. These methodologies are currently based on separation, identification and quantification of the different constituents by separation techniques having the best separating power like gas chromatography (GC). Owing to statistical peak overlap, the peak capacity of the separation system provided by conventional GC should be much higher than 3-4 times the actual number of components of a given FT sample [9]. Since the number of hydrocarbon isomers and type exponentially increases with the number of carbon atoms, conventional GC may become limited when dealing with the whole FT products. Besides, it is known that the narrow capillary columns (ID $<100 \mu \mathrm{m}$ ) coated with thick stationary phase film enable to provide the highest separation capacity [10]. Unfortunately, these high resolution capillary columns are not compatible with heavy fraction of the FT product (mainly, the $\mathrm{C}_{30}{ }^{+}$fraction) due to strong retention of heavy compounds towards stationary phases [10].

To overcome these limitations, various analytical approaches have been combined for fully characterizing FT samples, using multidimensional gas chromatography (MDGC) and/or mass spectrometry. MDGC was introduced in the 1980's and 1990's to overcome the limitation of conventional GC in term of separation power. According to the classical terminology in chromatography, separations are commonly called two - or multidimensional when separation of all or some selected groups of the sample's components are repeated in two or more analytical chromatographic columns of different selectivity [9-12]. Detailed description of principle and practical implementation of MDGC can be found elsewhere [11, 12].

The peak capacity of such two dimensional systems was shown to be the product of peak capacities provided by each dimension of separation. In the last decade, the implementation of comprehensive two-dimensional gas chromatography $(\mathrm{GC} \times \mathrm{GC})$ has been shown to be a very powerful tool to unravel complex mixtures $[9,11,12]$. Many studies underline the benefits of $\mathrm{GC} \times \mathrm{GC}$ in terms of peak capacity and sensitivity $[9,11-15]$, especially for the characterization of diesel cuts $[9,11-14]$ as well as for the control of the petrochemical processes (oligomerization of olefins...) [15]. Recently, light fraction of FT product $\left(\mathrm{C}_{10}-\mathrm{C}_{30}\right)$ have been analysed by $\mathrm{GC} \times \mathrm{GC}$ leading to innovative identification of oxygenates compounds and others products (olefins, paraffins) [15]. Unfortunately, this study was mainly focused on qualitative improvement and fails to distinguished molecular structure of oxygenated compounds. Recently, $\mathrm{GC} \times \mathrm{GC}$ has been used to differentiate cyclic olefins, dienes and cyclic dienes in high temperature Fischer-Tropsch -based fuels [16]. The effectiveness of selective catalytic hydrogenation in transforming dienes into olefins based on spectral data obtained by mass spectrometry should be studied in the future thanks to these data. Oxygenates compounds have been separated but the authors only focused on olefins.

This work aims thus at developing a new methodology of molecular analysis of FT samples, particularly the oxygenated sub-products based on the combination of various $\mathrm{GC}$ techniques. $\mathrm{GC} \times \mathrm{GC}$ has been investigated to achieve an extended molecular information. Other GC techniques were 
implemented to quantify the whole FT products. The last part of this study is devoted to the application of this new type of data to the understanding of the FT process. For that purpose, Fischer-Tropsch reaction synthesis has been carried out in presence of cobalt based catalyst in a slurry pilot plant. Distribution of the main products obtained via cobalt FischerTropsch synthesis, paraffin, and sub product like olefins and oxygenates is presented. Catalyst selectivity can be characterized in particular by three growth probability coefficients corresponding to each product family, i.e. paraffin, olefin and oxygenates products.

\section{EXPERIMENTAL}

\subsection{Analytical Methodology}

\subsubsection{Gas Fraction Analysis}

The gas fraction was analyzed by GC via on-line injection of the gaseous stream. The analytical method, which is widely used for refinery gas analysis (RGA) and is fully described in the ASTM standard methods D1945 and D1946, was performed [9]. It is based on a HP6890 chromatograph (Agilent Technologies) equipped with both flame ionization detector (FID) and thermal conductivity detector (TCD) and various packed columns and switching valves in order to allow the separation and quantification of carbon monoxide (CO), hydrogen $\left(\mathrm{H}_{2}\right)$, carbon dioxide $\left(\mathrm{CO}_{2}\right)$, and volatile hydrocarbons products (paraffins or olefins). Light alcohol traces are also detected and quantified.

\subsubsection{Hydrocarbons Distribution by Low Resolution Gas Chromatography (LR-GC)}

The quantification of the whole FT liquid sample, including the heavy fraction, was carried out using LR-GC to ensure the elution of the heavy fraction. A HP6890 GC equipped with FID was used with a non-polar metal coated capillary column $(10 \mathrm{~m} \times 0.53 \mathrm{~mm}$ ID $\times 5 \mu \mathrm{m}$, polydimethylsiloxane OV-1 WCOT Ultimetal, Chrompack). A $0.5 \mu \mathrm{L}$ FT sample was injected using on-column injector $\left(35^{\circ} \mathrm{C}\right)$ after two-fold dilution in carbon disulfide $\left(\mathrm{CS}_{2}\right)$. The oven temperature program was: $35^{\circ} \mathrm{C}(1 \mathrm{~min})$ to $380^{\circ} \mathrm{C}$ (then plateau at $380^{\circ} \mathrm{C}$ during $30 \mathrm{~min}$ ) at $10^{\circ} \mathrm{C} / \mathrm{min}$. The carrier gas $(\mathrm{He})$ was set at constant flow of $10 \mathrm{~mL} / \mathrm{min}$. FID detector set at $380^{\circ} \mathrm{C}$ was used for detection. $\mathrm{H}_{2}$, air and $\mathrm{He}$ (make up) flows were respectively 35,400 and $25 \mathrm{~mL} / \mathrm{min}$.

\subsubsection{Detailed Analysis of Major Compound Using High Resolution Gas Chromatography (HR-GC)}

Prior to the separation of the main compounds from the $\mathrm{C}_{30}{ }^{-}$ fraction on a high resolution capillary column, the heavy fraction of the FT sample $\left(\mathrm{C}_{30}{ }^{+}\right.$fraction), which was not compatible with the analytical column, was vented out by flow switching between the analytical column and a short pre-column. This pre-column ensures the separation of the FT sample according to increasing boiling point. For that purpose, a HP6890 GC equipped with FID and switching valves was used. HR-GC was carried out using a short precolumn $(0.5 \mathrm{~m} \times 0.20 \mathrm{~mm}$ ID $\times 0.5 \mu \mathrm{m}$, polydimethylsiloxane PONA, J\&W scientific), which was connected via a T connector to the non-polar high resolution capillary column $(50 \mathrm{~m} \times 0.20 \mathrm{~mm}$ ID $\times 0.5 \mu \mathrm{m}, \mathrm{OV}-1$, PONA, J\&W scientific). A $0.5 \mu \mathrm{L}$ FT sample was injected using split injector $\left(300^{\circ} \mathrm{C}\right)$. The oven temperature program was: $35^{\circ} \mathrm{C}(1 \mathrm{~min})-300^{\circ} \mathrm{C}$ (then plateau at $\left.30 \mathrm{~min}\right), 2^{\circ} \mathrm{C} / \mathrm{min}$. The carrier gas $(\mathrm{He})$ was set at constant flow of $1.5 \mathrm{~mL} / \mathrm{min}$. FID detector set at $350^{\circ} \mathrm{C}$ was used for detection. $\mathrm{H}_{2}$, air and $\mathrm{He}$ (make up) flows were respectively 35 , 400 and $25 \mathrm{~mL} / \mathrm{min}$.

\subsubsection{Analysis of Oxygenated Compounds at Trace Level Using Comprehensive Gas Chromatography}

$\mathrm{GC} \times \mathrm{GC}$ was carried out for the analysis of oxygenated compounds. The $\mathrm{GC} \times \mathrm{GC}$ system is a modified standard GC HP6890N (Agilent Technologies). In this work, GC $\times$ GC analysis was carried out with a non-polar column $(15 \mathrm{~m} \times$ $0.2 \mathrm{~mm} \times 0.5 \mu \mathrm{m}$, polydimethylsiloxane, PONA, J\&W scientific) in the first dimension, which was connected to a secondary column: BPX 50 ((50\% phenyl)-polysilphenylenesiloxane, $\mathrm{SGE}, 1.0 \mathrm{~m} \times 0.1 \mathrm{~mm} \mathrm{ID} \times 0.1 \mu \mathrm{m})$. The modulator was a dual stage carbon dioxide jet modulator built in house as described elsewhere [15]. FID detector set at $320^{\circ} \mathrm{C}$ was used for detection. $\mathrm{H}_{2}$, air and $\mathrm{He}$ (make up) flows were respectively 35, 400 and $25 \mathrm{~mL} / \mathrm{min}$. After acquisition, FID signals were exported as CSV-files from the Chemstation for data handling. Contour plotting, peak collection, retention time measurement, peak integration and the report were done using a in-house software named $2 \mathrm{DChrom}^{\mathrm{TM}}$. Automatic peak finding and contour plots fitting were implemented to $2 \mathrm{DChrom}^{\mathrm{TM}}$ in order to improve reproducibility and accuracy of integration.

The GC $\times$ GC Time of flight Mass spectrometry (TOFMS) system consisted of a $6890 \mathrm{~N}$ (Agilent Technologies) gas chromatograph and a Pegasus IV time of flight mass spectrometer (LECO). A $(15 \mathrm{~m} \times 0.2 \mathrm{~mm}$ ID $\times 0.5 \mu \mathrm{m})$ PONA column was used as the first dimension column. The second dimension separation was achieved on a $(1.0 \mathrm{~m} \times$ $0.1 \mathrm{~mm} \mathrm{ID} \times 0.1 \mu \mathrm{m}$ ) BPX 50 column. The separation was carried out at a constant pressure of 2.5 bars. Electron impact (EI) ionization was performed at $70 \mathrm{eV}$, the acquisition frequency was $100 \mathrm{~Hz}$ in a mass range of 35 to $500 \mathrm{amu}$ and a multi-plate voltage of $-1400 \mathrm{~V}$ was applied. Identification of compounds was achieved by comparing acquired mass spectra with NIST 2.0 (2002) library using Pegasus software. 


\subsection{Catalyst Preparation and Testing}

\subsubsection{Catalyst Preparation}

The cobalt catalyst is prepared by wet impregnation of aqueous cobalt nitrate on a commercial alumina from Condea, representing a total cobalt loading of $13 \mathrm{wt} \%$. Then the sample is dried and calcined in air at $400^{\circ} \mathrm{C}$. The support particle size distribution is chosen in a specific range according to its use in slurry conditions, in between 10 and $200 \mu$. Before use, the catalyst (oxide precursor) is reduced under hydrogen atmosphere at $400^{\circ} \mathrm{C}$.

\subsubsection{Catalyst Test}

The Fischer-Tropsch synthesis is carried out in a slurry pilot plant equipped with a CSTR reactor (volume $1 \mathrm{~L}$ ), continuously fed by syngas ( $\mathrm{CO}$ and $\mathrm{H}_{2}$ mixture) and stirred (maintained under mechanical stirring). The reactor is initially filled with a start-up solvent and pre-reduced catalyst is introduced under inert atmosphere. After an initial catalyst conditioning step where end of catalyst construction occur under syngas $[17,18]$ in the slurry phase, the Fischer-Tropsch reaction is performed at $230^{\circ} \mathrm{C}, \mathrm{H}_{2} / \mathrm{CO}$ feed ratio of 2.0 , under 20 bar of pressure. Gradually, the initial start-up solvent is replaced by the liquid products, commonly named FischerTropsch waxes. The gas effluent recovered at the top of the reactor is, in several steps, condensed and separated from liquid products, both hydrocarbons products and aqueous phase products, before on line analyses. All the liquid products, both hydrocarbon and aqueous phase products, are weighed and analysed. After some time on stream, when the initial solvent is almost entirely purged, the distribution of whole Fischer-Tropsch products is available by doing complete material balance taking into account all the input and the output of the reactor, including gas and liquid, feed and products. Usually, complete material balances are performed during 24 to $48 \mathrm{~h}$.

The operating conditions have been well adapted and controlled in order to avoid catalyst damaged. Stabilized catalytic performances were reached. The composition of liquid hydrocarbons products has been followed with time. The start-up solvent residual concentration has been determined and the results are presented in Table 1. They show that after 188 hours, the n-octadecane $\left(\mathrm{n}-\mathrm{C}_{18}\right)$ is almost entirely purged (concentration below $6 \mathrm{wt} \%$ ) and at $260 \mathrm{~h}$ of run, a steady state operation is reached and the products are fully representative of the Fischer-Tropsch reaction selectivity.

The reaction conditions are summarized in Table 2 and the detailed data concerning the material balance, from; which the products distribution has been provided is also given. The good accuracy of total weight material balance and also $\mathrm{C}, \mathrm{H}, \mathrm{O}$ material balance can illustrate the good reliability of the results obtained.
TABLE 1

Evolution of liquid hydrocarbon product composition with time on stream

\begin{tabular}{c|c|c}
\hline $\begin{array}{c}\text { Time on stream } \\
\text { (h) }\end{array}$ & $\begin{array}{c}\text { Run } \\
(\#)\end{array}$ & $\begin{array}{c}\text { Concentration of } n-\mathrm{C}_{18} \text { in liquid } \\
\text { hydrocarbons products (wt\%) }\end{array}$ \\
\hline 20 & 1 & 52.7 \\
\hline 43 & 2 & 46.5 \\
\hline 94 & 3 & 25.7 \\
\hline 140 & 4 & 10.6 \\
\hline 188 & 5 & 6.0 \\
\hline 260 & 6 & 3.9 \\
\hline 284 & 7 & 3.9 \\
\hline
\end{tabular}

TABLE 2

Operating conditions and detailed data of material balance

\begin{tabular}{l|c}
\hline Time on stream $(\mathrm{h})$ & 188 \\
\hline Material balance duration $(\mathrm{h})$ & 43 \\
\hline Syngas flow rate $(\mathrm{Nl} / \mathrm{h})$ & 150 \\
\hline Temperature $\left({ }^{\circ} \mathrm{C}\right)$ & 230 \\
\hline Pression $($ bar $)$ & 20 \\
\hline Inlet $\mathrm{H}_{2} / \mathrm{CO}$ ratio & 2.0 \\
\hline CO conversion $(\%)$ & $56 \%$ \\
\hline Material balance $(\mathrm{wt} \%)$ & 100.2 \\
$\mathrm{C}$ material balance $(\mathrm{mol} \%)$ & 101.1 \\
$\mathrm{H}$ material balance $(\mathrm{mol} \%)$ & 98.0 \\
O material balance $(\mathrm{mol} \%)$ & 100.0 \\
\hline
\end{tabular}

\section{RESULTS AND DISCUSSION}

\subsection{Quantification of the Main Compounds from FT Samples by Combination of LR-GC and HR-GC}

The Fischer-Tropsch liquid samples were injected in both LR-GC and HR-GC systems for quantification of the main compounds (paraffins and olefins).

\subsubsection{Global Quantification of $\mathrm{C}_{30}$ - Fraction}

Prior to HR-GC analysis, LR-GC was carried out for quantification of the mass concentration of $\mathrm{C}_{30}{ }^{-}$fraction on the overall FT samples. For that purpose, it is compulsory to provide a complete elution by GC of the FT sample. In order to ensure the elution of heaviest compounds of the FT samples, the use of a thin film of stationary phase and a wide bore capillary column coated with stainless steel, which is thermal resistive, seemed to be the most judicious option in order to reduce their retention $[9,12]$. 
Using the optimized operating conditions described in Section 1.1.3, elution of normal paraffin with 90 carbons was achieved using a final oven temperature of $380^{\circ} \mathrm{C}$. However, this low stationary phase's thickness (film thickness = $0.10 \mu \mathrm{m})$ presents an important drawback: the combination between a thin film and a large internal diameter of the analytical column strongly decreases the separation capacity. Overlapping of compounds consequently occurs, leading to inaccurate separation between the main classes of compounds (paraffins, olefins, alcohols and other derivatives).

Therefore, only the whole distribution of hydrocarbons was achieved by LR-GC, owing to the fact that all the compounds were alleged to have similar response factor for the FID detector. The compounds were quantified by direct integration using internal normalization. The chromatographic profile, as shown in Figure 1, was compared to standard mixture of n-paraffins in order to identify the elution peaks of nalkanes, which could be clearly identified. The mass concentration of $\mathrm{C}_{30}-$ fraction was then quantified. The elution peaks for $n-\mathrm{C}_{10}$ and $n-\mathrm{C}_{30}$ have been highlighted on the chromatogram. Minor components can not be distinguished from the baseline.

\subsubsection{Analysis of Paraffins by HR-GC in the $\mathrm{C}_{30}{ }^{-}$Fraction}

A better characterization of the main compounds from FT samples required the use of HR-GC system. Only the $\mathrm{C}_{30}{ }^{-}$ fraction was introduced to the high resolution analytical column while the compounds having higher carbon number were retained in a pre-column and back-flush to the vent

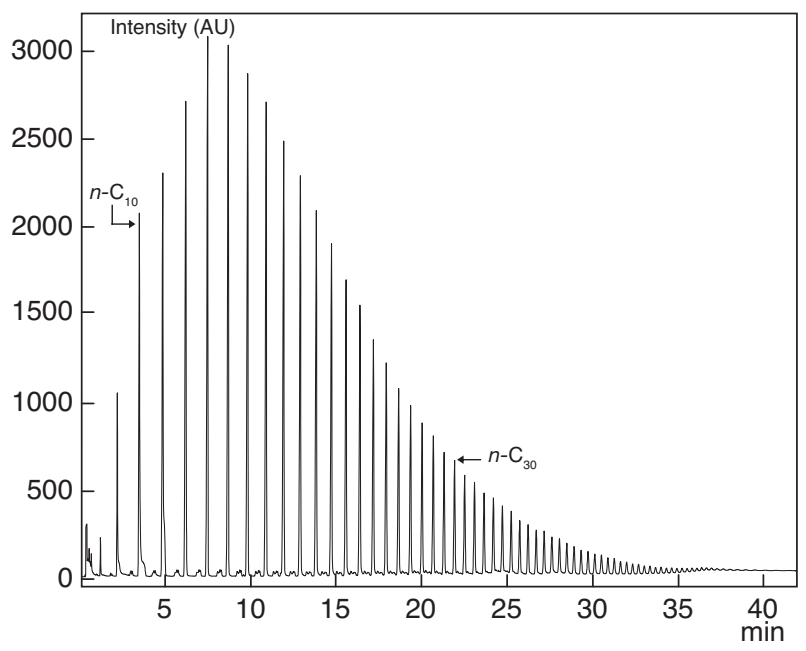

Figure 1

Chromatograms of a FT product sample obtained by LR-GC (elution peaks of $n-\mathrm{C}_{10}$ and $n-\mathrm{C}_{30} \mathrm{n}$-alkanes are indicated). $n$ - $\mathrm{C}_{10}$ : n-decane, $n$ - $\mathrm{C}_{30}$ : n-tricontane.

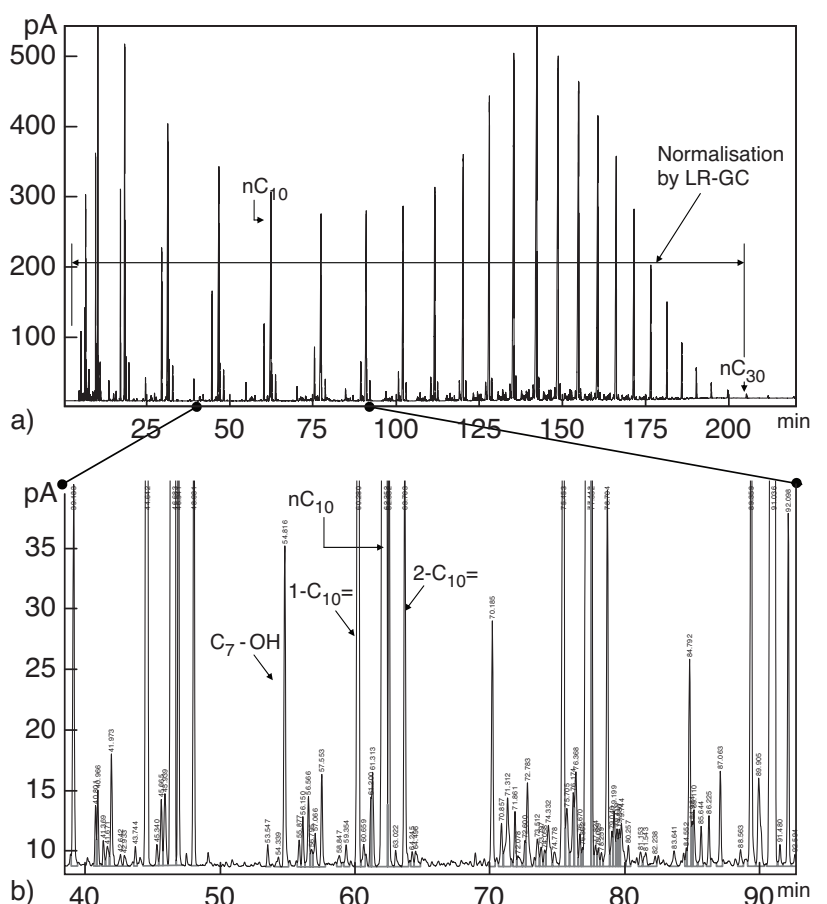

Figure 2

Chromatograms of a FT product sample obtained in by HR-GC a). An enhanced view of the elution zone corresponding to $n-\mathrm{C}_{10}$ is shown b).

$n$ - $\mathrm{C}_{10}$ : n-decane, $\mathrm{C}_{7}-\mathrm{OH}$ : heptane alcohol, $1-\mathrm{C}_{10}=:$ 1-decene, 2- $\mathrm{C}_{10}=:$-decene.

(see Sect. 1.1.3). The operating conditions were similar to the conditions described by the ASTM standard method D6733 for detailed hydrocarbon analysis of gasoline, leading to detailed chromatograms.

A typical chromatogram of the $\mathrm{C}_{30}{ }^{-}$fraction obtained by HR-GC is shown in Figure 2a, the elution zone corresponding to $\mathrm{C}_{30}{ }^{-}$fraction is indicated. Fraction of heavy compounds has been introduced in the analytical column but their concentration was decreasing when carbon number increased: most of them were back-flushed from pre column. Figure $2 b$ represents an enhanced view of Figure $2 a$, in the elution zone corresponding from $n-\mathrm{C}_{11}$ to $n$ - $\mathrm{C}_{13}$. It indicates that an almost complete separation was achieved between linear n-olefins, iso olefins and linear n-paraffins. Linear alpha alcohol was also clearly separated from other compounds.

As hydrocarbons have been separated individually, it was possible to define a specific response factor for each compound in order to obtain a more accurate quantification. Internal quantification was carried out. However, only the lighter fraction was eluted from HR-GC, as previously 
discussed. The overall quantification of $\mathrm{C}_{30}{ }^{-}$fraction was then re-normalized by the value determined by LR-GC for this fraction, in order to take account of the heavy fraction.

Nevertheless, HR-GC was not able to provide the separation of these mains components ( $\mathrm{n}$ and iso-olefins, $\mathrm{n}$ and isoparaffins and alpha alcohols) from the other oxygenated compounds, due to:

- their low level of concentration and,

- their retention time, leading to overlap by other species.

Even though alcohols with hydroxyl group substituted in position 1 were identified in HRGC, the lack of separation power leads to a conflicting integration and it prevents from a better understanding of FT process. Comprehensive gas chromatography $(\mathrm{GC} \times \mathrm{GC})$ was then investigated for dealing with the quantification of trace of oxygenated compounds.

\subsection{Quantification of the Oxygenated Compounds from FT Samples by Comprehensive GC}

\subsubsection{GC $\times$ GC Principle and Interest for Unravelling the Deep Nature of FT Samples}

The principle of $\mathrm{GC} \times \mathrm{GC}$ is based on the hyphenation of two capillary GC columns of different selectivity connected through a modulation device. This interface enables sampling, focusing by trapping successive fractions of the effluent coming from the first column in narrow bands onto the second column and re-injection in a continuous way of sharp fractions of the first column's effluent into the second column. In that case, the entire sample is subjected to the two separation procedures and reaches the detector. Thus, two solutes co-eluting in the first separation may be separated in the second dimension provided that their interactions with the second stationary phase are different. Hence, a series of very fast separations in the second dimension is achieved simultaneously to the first-dimension separation. The raw modulated signal recorded by the detector is then processed for visualisation of $2 \mathrm{D}$ chromatograms where peaks are displayed as spots in a retention plane described as the first-dimension retention time in the $x$-axis and the second-dimension retention time in the $y$-axis. Intensity of peaks is indicated by colour gradation and this configuration can be viewed as the cartography of a sample. A 3D reconstruction may also be obtained, the third $z$-axis representing the peak intensity.

Clearly, the analysis of oxygenated compounds contained in the FT complex samples stands to benefit from the development of this extremely powerful separation technique. Compared to conventional HR-GC, the main advantages of comprehensive $\mathrm{GC} \times \mathrm{GC}$ are $[11,12]$ :

- a much higher peak capacity, which involves an improved separation of oxygenated components from other overlapping hydrocarbon. It would provide optimal separation of complex mixtures into well-separated individual peaks (peak capacities of 30000 and integration of more than 5000 peaks are currently achieved),

- a better sensitivity due to the refocusing process in the thermal modulator (see [12]). This allows the accurate determination of low concentrations of oxygenated components,

- if efficient combination of selectivity are used, chemically related compounds show up as ordered structures, which greatly facilitates group-type analysis and the provisional classification of unknowns [12-14]. It may provide boiling point range distribution and polarity distribution and thus increase the amount of information generated per unit time.

\subsubsection{Analytical Strategy for Unravelling the Deep Nature of FT Samples}

The following analytical strategy has been carried out:

- optimization of separation of model compounds (investigation of nature of stationary phases and column features) in order to provide the better separation of compounds according to their type (i.e. polarity or affinity towards a polar stationary phase) and their boiling points (i.e. carbon number or affinity toward an non polar stationary phase),

- application to representative samples from FT process,

- identification of the structure of oxygenated compounds by mass spectrometry via Time of flight (TOF) spectrometer hyphenated to $\mathrm{GC} \times \mathrm{GC}$,

- quantification by $\mathrm{GC} \times \mathrm{GC}$ using FID detector and response factors.

\subsubsection{Identification of Oxygenates by $G C \times G C / T O F-M S$}

The goal of this part is the identification and quantification of oxygenated compounds generally coeluting with hydrocarbons in HR-GC. For the analysis of oxygenates by means of $\mathrm{GC} \times \mathrm{GC}$, non polar / polar combination of stationary phases usually increases the occupation of the two-dimensional chromatographic plane and make easy the interpretation of separation plane, especially when the distribution according to the number of carbon within each chemically related class of hydrocarbon has to be determined [15]. Conventional two dimensional chromatographic conditions have then been optimised. The discussion of this optimisation is out the scope of this paper but similar discussion can be found elsewhere [13-15]. Columns combination was consisting in a first non polar column (polydimethylsiloxane), which allows a first separation according to the volatility or boiling point. A second polar column consisting of polysilphenylenesiloxane - including 50\% of phenyl group - (BPX 50) was used for separating compounds according to their polarity (see Sect. 1.1.4). Again, the heavy fraction was not compatible with the separation system and it was vented out by backflushing the flow before introduction onto the analytical columns. 


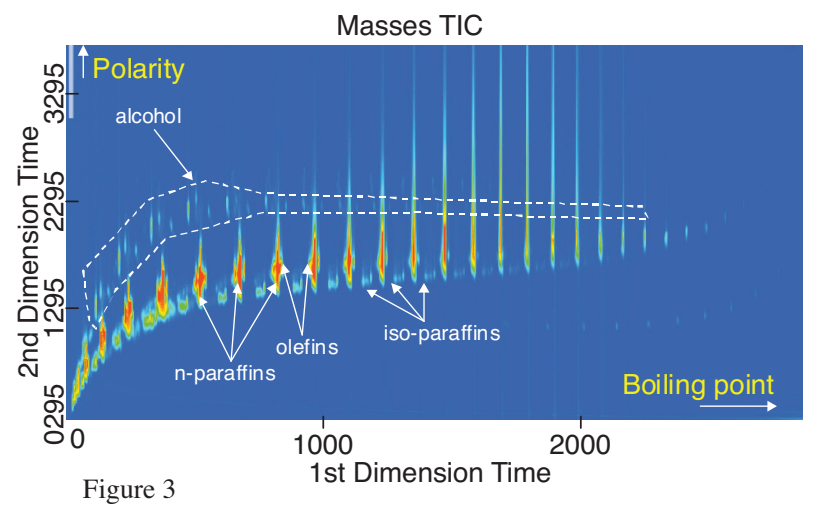

2D-Chromatogram of the $\mathrm{C}_{30}{ }^{-}$fraction of FT product sample obtained by $\mathrm{GC} \times \mathrm{GC} / \mathrm{TOF}-\mathrm{MS}$ (total ionic current).

The two-dimensional chromatogram of a representative FT sample obtained, using these chromatographic conditions, is presented in Figure 3. It was obtained by the acquisition of the total ionic current (TIC) of the spectrometer, which allows an "universal" answer of the TOF-MS: all the mass spectra were recorded. The chromatogram clearly shows that the optimised chromatographic conditions involves that oxygenates are organized into a distinct band of compounds from n-paraffins, iso-paraffins and olefins. Indeed, they have an increased polarity and, then, an increased retention onto the second dimension due to strong interaction towards the stationary phase. However, poor separation between oxygenates themselves is observed on the second dimension, indicating that their polarity was quite similar for all the structures. Besides, the intensity of elution peaks was quite weak compared to hydrocarbon elution peaks. Finally, n-paraffins elution peaks are tailing due to very bad solvation and they are overloading in the secondary stationary phase.

As their retention was very close, chemical structures of oxygenates need to be identified by TOF-MS detector using recording among a selective $\mathrm{m} / \mathrm{z}$ ratio. Figure 4 shows chromatograms obtained by $\mathrm{GC} \times \mathrm{GC} / \mathrm{TOF}-\mathrm{MS}$. It reveals that various oxygenated compounds are present in the same retention area:

- Figures 4a and 4b present two selected ion chromatograms of the $\mathrm{C}_{30}{ }^{-}$fraction of FT sample using specific masses 74 and 60, for alkyl-methyl-esters and for alkyl-carboxylic acid, respectively. Isomers of esters and carboxylic acids were eluted in two different elution bands. Note that alkanes' elution peaks were removed. Similar identification was performed to evidence the elution zone for alcohol and ketone derivatives,

- finally, Figure $4 \mathrm{c}$ reveals the different elution zones for the different classes of oxygenated compounds for a given carbon number. To ease the comparison, the band corresponding to carboxylic acids has been drawn on the two-dimensional chromatogram.
Figure $4 \mathrm{c}$ shows that the different oxygenated compounds are organised within the retention plane upon increasing polarity (methyl ester $<$ ketone $<$ alcohol < carboxylic acid). Indeed, the carboxylic function awards most polarity and it results in the most polar molecules $[10,15]$ which are likely to interact through stronger induced dipole-permanent dipole with the stationary phase of the BPX 50 column used in the second dimension.
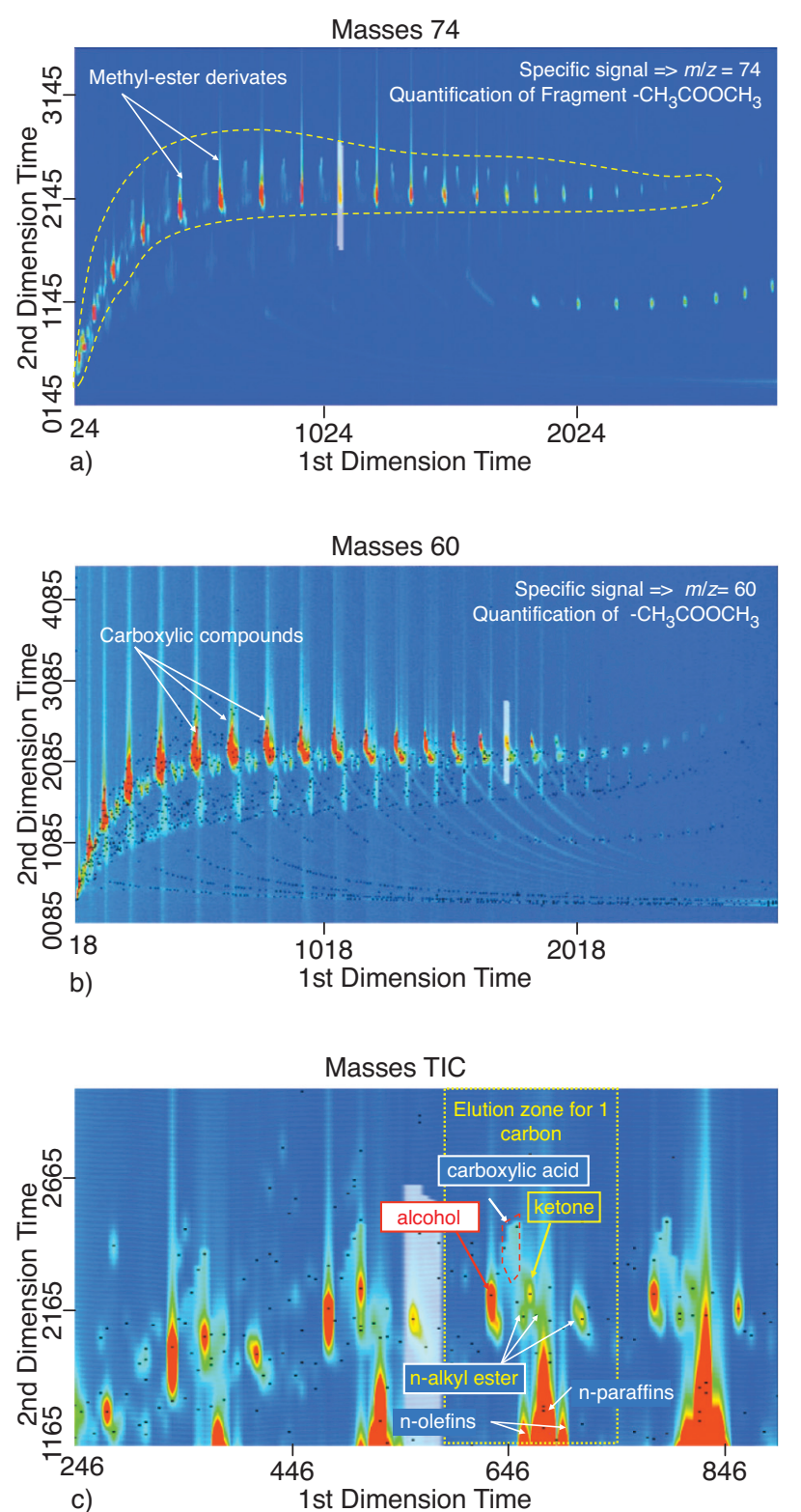

Figure 4

2D-Chromatograms of the $\mathrm{C}_{30}{ }^{-}$fraction of FT product sample obtained by GC $\times$ GC/TOF-MS using specific signal for $\mathrm{m} / \mathrm{z}=$ $74 \mathrm{a})$ and $m / z=60 \mathrm{~b}$ ). An enhanced view of chromatogram from total ionic current in the range of one carbon is shown c). 

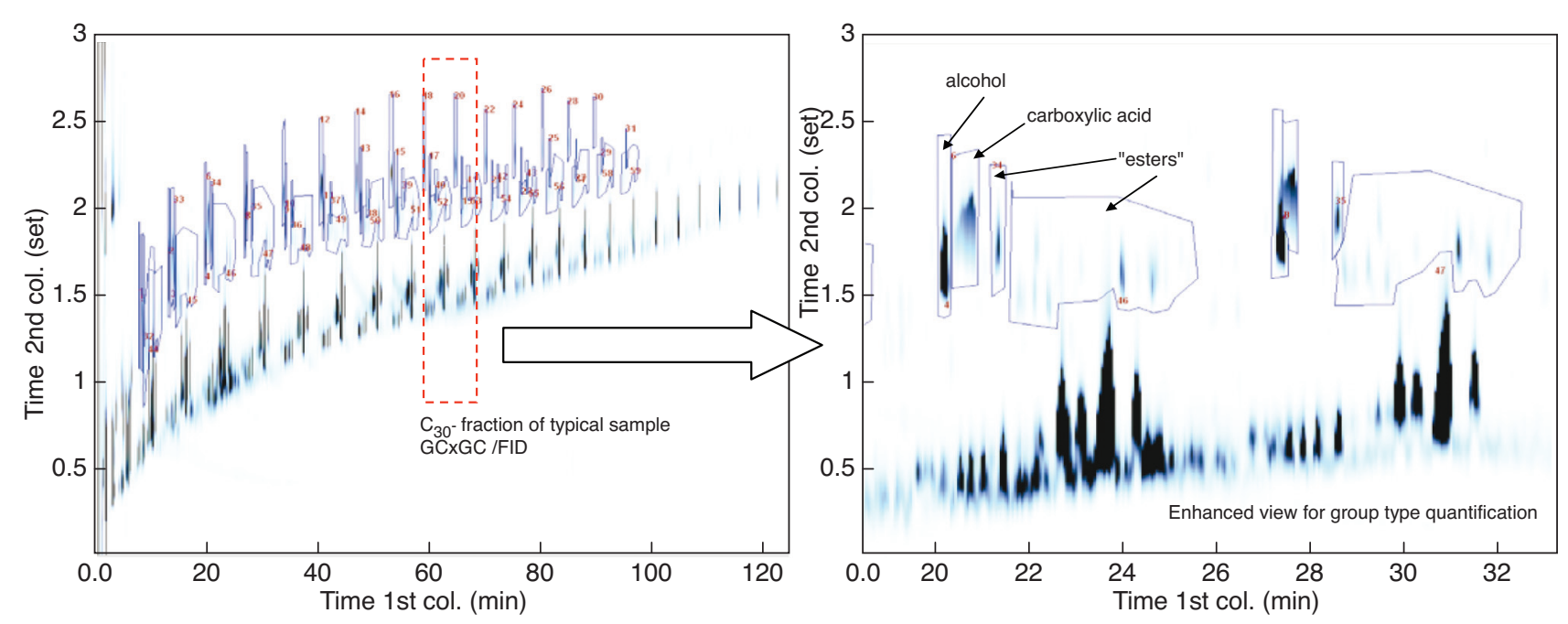

Figure 5

2D-Chromatograms of the $\mathrm{C}_{30}{ }^{-}$fraction of FT product sample obtained by $\mathrm{GC} \times \mathrm{GC} / \mathrm{FID}$ a). The clusters for each type of oxygenated compounds are indicated. An enhanced view of total ionic current in the range of one carbon is shown b).

Finally, $\mathrm{GC} \times \mathrm{GC}$ succeeds in separating and identifying the main elements of the molecular structure of oxygenates compounds (type of oxygenated function, number of carbon atoms). However, MS detector fails to provide unique structure of each isomer, such as the nature of alkyl group, which are all eluted at similar retention times for the two axes due to similar boiling point and polarity.

\subsubsection{Quantification of Oxygenates by GC $\times$ GC/FID}

Even though the identification of oxygenated compounds was performed on a $\mathrm{GC} \times \mathrm{GC} / \mathrm{TOFMS}$ system, the quantification of the different classes of compounds was carried out using a $\mathrm{GC} \times \mathrm{GC} / \mathrm{FID}$ system.

Figure 5 shows a typical 2D chromatogram, including the determination of the elution zone for all the linear alcohol, carboxylic acid and esters, where were gathered ketones and methyl or ethyl alkyl esters. Again, it was possible to implement specific response factors for each type of compound in order to obtain a more accurate quantification of each family for a given carbon number. Internal quantification was used after re-normalization due to the removal of $\mathrm{C}_{30}{ }^{+}$fraction.

A comparison of the distribution of linear alcohol obtained by $\mathrm{GC} \times \mathrm{GC}$ and HR-GC analysis is shown in Figure 6, indicating that the distribution of these main oxygenates compounds appears as more regular from the data obtained by HR-GC, thanks to more accurate quantification.

As a conclusion of analytical part of this work, this regular wt $\%$ distribution of main oxygenated compounds illustrates good reliability of the results obtained by combination of these various analytical devices.

\section{APPLICATION}

Thanks to the comprehensive analyses of the FT products, a detailed quantitative distribution of the whole FT products was obtained and was expressed by carbon breakdown.

\subsection{ASF Curves for Hydrocarbons}

FT samples obtained using the protocol described in section 1.2 were then fully characterized : the total products distribution results are presented in Table 3 and 4. For each carbon number range, the hydrocarbon products were gathered according to their main family (Paraffin, Olefin, Oxygenates). Oxygenates were not distinguished by type. The distribution of the product is also presented Figure 7.

\section{TABLE 3}

Whole Fischer-Tropsch products distribution (wt \%) obtained by combination of HR-GC and GC $\times$ GC

\begin{tabular}{c|c|c|c|c|c}
\hline Hydrocarbon & $n$ & Paraffin & Olefin & Oxygenates & Total \\
\hline $\mathrm{C}_{1}$ & 1 & 8.17 & & 0.14 & 8.32 \\
$\mathrm{C}_{2}-\mathrm{C}_{4}$ & $2-4$ & 5.18 & 4.68 & 0.49 & 10.35 \\
$\mathrm{C}_{5}-\mathrm{C}_{9}$ & $5-9$ & 11.62 & 4.42 & 0.61 & 16.64 \\
$\mathrm{C}_{10}-\mathrm{C}_{13}$ & $10-13$ & 12.10 & 1.72 & 0.61 & 14.43 \\
$\mathrm{C}_{14}-\mathrm{C}_{21}$ & $14-21$ & 22.73 & 1.09 & 0.68 & 24.49 \\
$\mathrm{C}_{22}-\mathrm{C}_{24}$ & $22-24$ & 4.58 & 0.07 & 0.12 & 4.78 \\
$\mathrm{C}_{25}{ }^{+}$ & $25-90$ & 20.91 & 0.06 & 0.02 & 20.99 \\
$\mathrm{C}_{5}{ }^{+}$ & & 71.94 & 7.36 & 2.03 & 81.34 \\
$\mathrm{C}_{9}{ }^{+}$ & & 61.89 & 3.13 & 1.62 & 66.64 \\
\hline$T_{0}{ }^{+}$ & & 85.29 & 12.05 & 2.66 & 100 \\
\hline
\end{tabular}




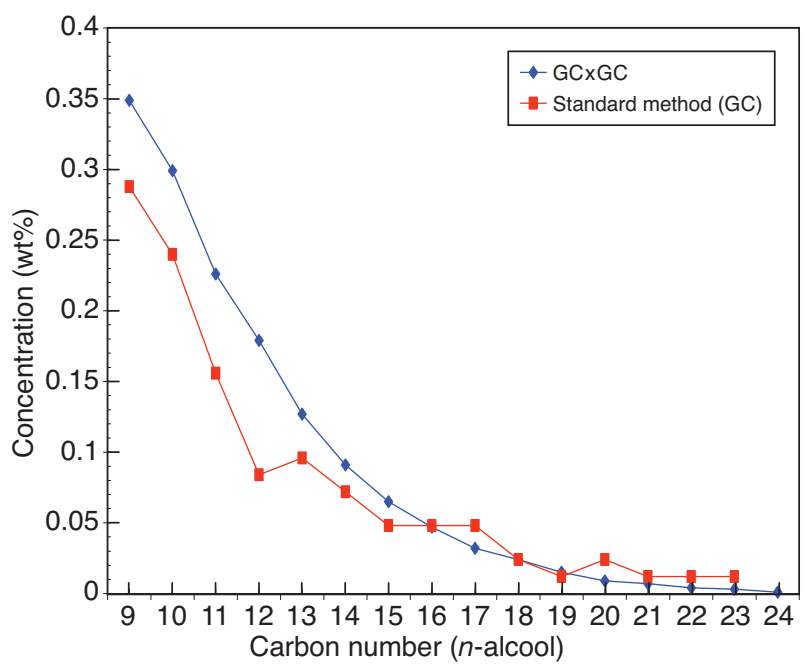

Figure 6

Distribution of linear alcohols obtained by $\mathrm{GC} \times \mathrm{GC}$ and $\mathrm{HR}$ GC for a FT product sample versus carbon number.

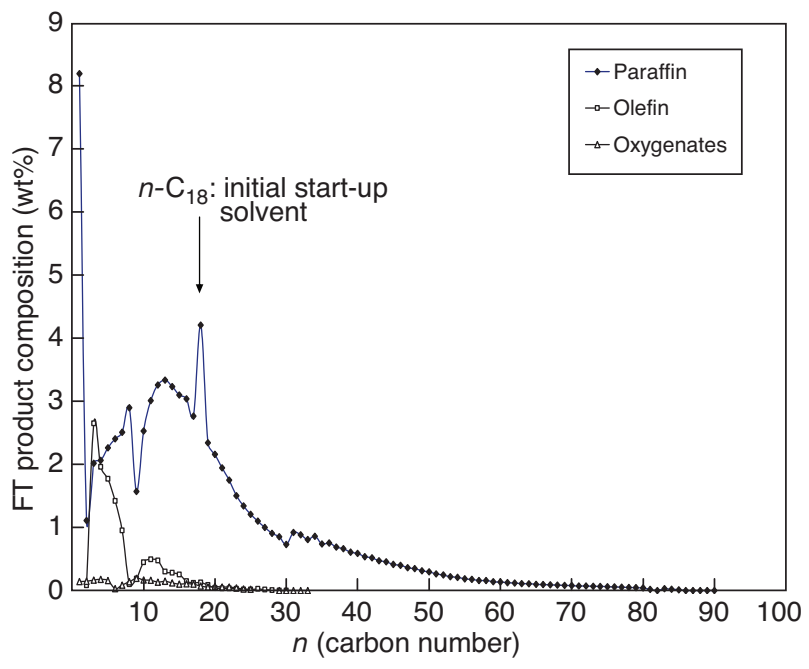

Figure 7

Distribution of the class of compounds from a FT product sample versus carbon number.
TABLE 4

Chemical class distribution of Fischer-Tropsch products versus carbon number (wt $\%)$

\begin{tabular}{c|c|c|c|c}
\hline Hydrocarbon & Paraffin (\%) & Olefin (\%) & Oxygenates (\%) & Total \\
\hline $\mathrm{C}_{1}$ & 98.3 & 0 & 1.7 & 100 \\
\hline $\mathrm{C}_{2}-\mathrm{C}_{4}$ & 50 & 45.3 & 4.7 & 100 \\
\hline $\mathrm{C}_{5}-\mathrm{C}_{9}$ & 69.8 & 26.6 & 3.6 & 100 \\
\hline $\mathrm{C}_{10}-\mathrm{C}_{13}$ & 83.9 & 11.9 & 4.2 & 100 \\
\hline $\mathrm{C}_{14}-\mathrm{C}_{21}$ & 92.8 & 4.5 & 2.8 & 100 \\
\hline $\mathrm{C}_{22}-\mathrm{C}_{24}$ & 95.9 & 1.5 & 2.5 & 100 \\
\hline $\mathrm{C}_{25}{ }^{+}$ & 99.6 & 0.3 & 0.1 & 100 \\
\hline
\end{tabular}

The Fischer-Tropsch reaction is a step growth polymerisation originally described mathematically by Schulz and Flory [6]. The products distribution can be described by the chain growth probability factor, or growth factor, usually named alpha $(\alpha)$ or $\mathrm{p}$ (for chain propagation by opposite to chain termination):

$$
W_{n}=\left(\ln ^{2} \alpha\right) n \alpha^{n}
$$

where $W_{n}$ is the weight fraction of the products with $n$ carbon number and $\alpha$ the chain growth probability factor.

From Equation (1) and its logarithmic expression, the chain growth probability coefficient can be determined through the ASF plot Log $W_{n} / n$ versus $n$. According to the equation, this plot should give a straight line which slope is equal to $\log \alpha$.
From our distribution data (Fig. 7) and taking into account for each carbon number the sum of all hydrocarbons, paraffin, olefin and oxygenates, the ASF plot obtained present a negative deviation as frequently reported (Fig. $8 a$ ). In that case, two alpha values can be determined on respectively carbon range $\mathrm{C}_{3}-\mathrm{C}_{10}$ and $\mathrm{C}_{10}-\mathrm{C}_{85}$. For determination, $n-\mathrm{C}_{18}$ has been taken off from the linear $\mathrm{C}_{10}-\mathrm{C}_{85}$ equation because of its slight over-estimation due to residual initial start-up solvent. By taking into account in the ASF expression the sum of all the $\mathrm{Cn}$ hydrocarbons, independently of its family, it is assumed that the chain growth propagation is common at catalyst surface for all hydrocarbons formed. Chain growth occurs formally by the addition of a surface methylene species to an adsorbed alkyl group, leading to another adsorbed alkyl group. The family distinction occur in a second step according to reactivity of the later alkyl group:

- hydrogen addition leads to formation of n-paraffin,

- $\beta$-hydrogen abstraction leads to $\alpha$-olefin formation.

According to mechanism scheme reported, especially by Iglesia [4], $\beta$-hydrogen abstraction is a reversible chain termination step in which $\alpha$-olefin readsorption could lead to reinitiation of alkyl surface chains. In addition, $\alpha$-olefin could be involved in secondary reactions such as hydrogenation, hydrogenolysis and hydroformylation, the later leading in particular to alcohols formation.

However, looking at the deviation observed in Figure 8a, it seems quite difficult to attribute the strict break of the ASF plot observed at $C_{10}$ to a general mechanism of reactions which can happen at each step of chain growth i.e. all carbon number length and not $\mathrm{C}_{10}$ alone. Besides, it has to be noticed that initial deviation part $(n \leq 10)$ in the ASF 

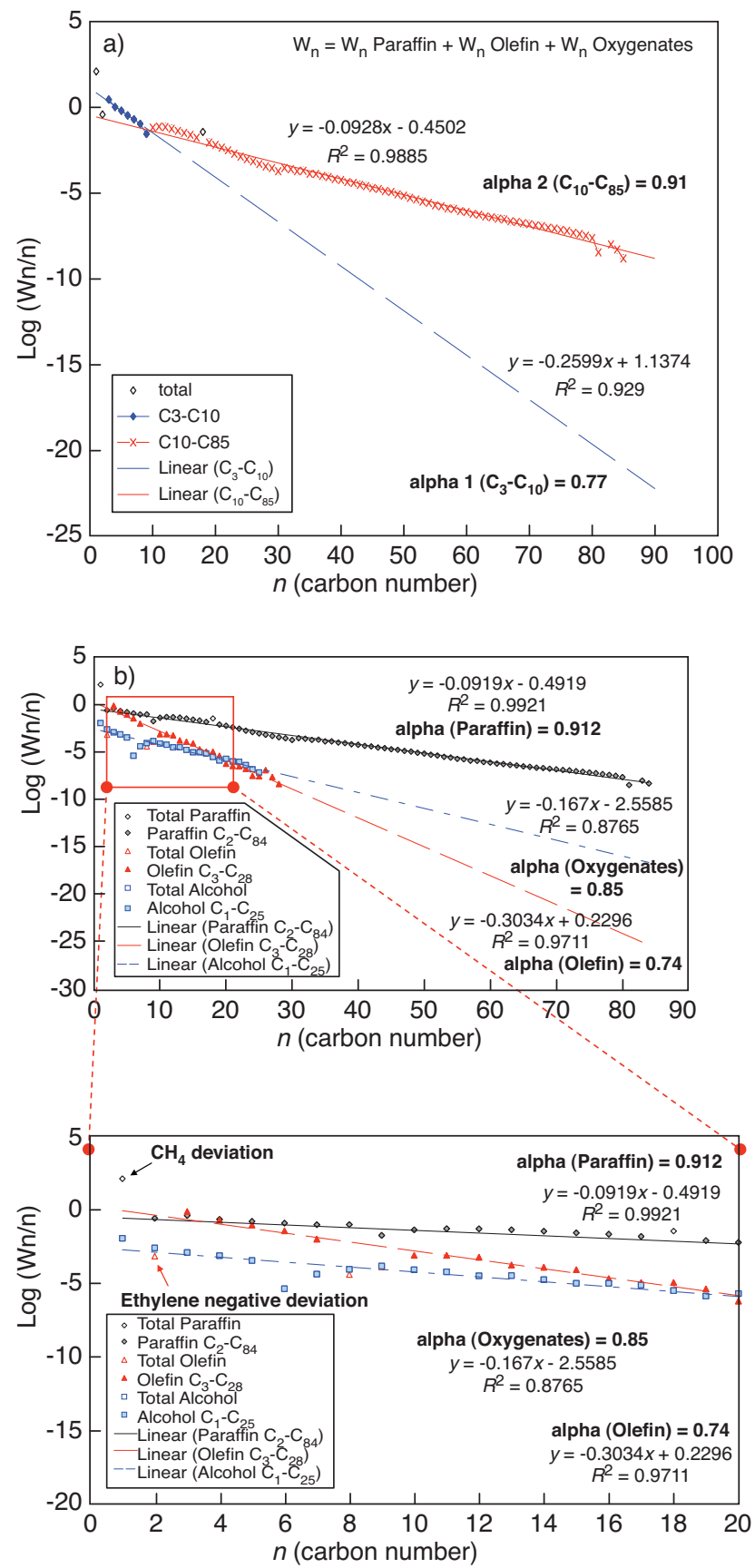

Figure 8

ASF plot based on all hydrocarbons formed $\left(W_{n}=\Sigma W_{n}\right.$ (Paraffin, Olefin \& Oxygenates)) a), ASF plots for each hydrocarbon products family $b$ ).

plot correspond to carbon number range where olefin proportion is significant. Indeed, olefin proportions represent almost half part in the $\mathrm{C}_{2}-\mathrm{C}_{4}$ range and almost one third in the $\mathrm{C}_{5}-\mathrm{C}_{9}$ hydrocarbon fraction (see Tab. 4). Thus, it may be quite clear that the deviation observed in Figure 8 can be linked with olefin products as reported by many authors [2-4]. This observation leads us to distinguish paraffin and olefin and, in fine, each family products.

\subsection{ASF Curves for Hydrocarbons Families}

Based on a different reaction mechanism hypothesis, we have distinguished the chain growth process independently for each hydrocarbons family. That is to say we have plotted the ASF distribution respectively for paraffin products, olefin products and oxygenated products:

- plot 1, related to paraffin products, is the plot of Log $\left(W_{n, \mathrm{p}} / n\right)$ versus $n$, where $W_{n, \mathrm{p}}$ is the weight fraction of the paraffin products with $n$ carbon number,

- plot 2, related to olefin products, is the plot of Log $\left(W_{n \text {,olef }} / n\right.$ ) versus $n$, where $W_{n \text {,olef }}$ is the weight fraction of the olefin products with $n$ carbon number

- plot 3, related to oxygenates products is the plot of Log ( $\left.W_{n, \text { oxyg }} / n\right)$ versus $n$, where $W_{n, \text { oxyg }}$ is the weight fraction of the oxygenate products with $n$ carbon number

As a result, three linear plots are obtained as it is illustrated in Figure 8b. In particular in case of paraffin plot, a very high linear regression coefficient is obtained (>0.99), linked to the numerous data input (paraffins quantified up to $n-\mathrm{C}_{84}$ ) but revealing also a very accurate analytical method for liquid hydrocarbon products (especially waxes). From the slope of each plot, three chain growth coefficients, corresponding to each hydrocarbons family, can be determined, named alpha (paraffin), alpha (olefin) and alpha (oxygenates).

When looking at Figure $8 \mathrm{~b}$ in details, it is observed a lack in the distribution of $\mathrm{C}_{9}$ paraffin products, $\mathrm{C}_{8}-\mathrm{C}_{9}$ compounds in case of olefin and $\mathrm{C}_{6}-\mathrm{C}_{7}$ oxygenates compounds. This under-estimation of products could be linked with some loss of volatile compounds when liquid hydrocarbon products are recovered or analysed. Most probably (our preferred hypothesis), this can be linked with chromatography detection limit of the highest hydrocarbons tracers present in the gas effluent or default in the lowest peak integration. It is the case for $\mathrm{C}_{8}-\mathrm{C}_{9}$ hydrocarbon paraffin and olefin fraction and, concerning oxygenates, 1-pentanol is the last alcohol detected in the gas effluent analysis $\left(\mathrm{C}_{6}-\mathrm{C}_{7}\right.$ alcohols not detected). The underestimation appears more pronounced in case of olefin than in paraffin (only $\mathrm{C}_{9}$ concerned) probably because of olefin lower concentration more affected by GC detection limit. Another anomaly is the little $n$ - $\mathrm{C}_{18}$ paraffin excess, already discussed, due to slight residual start-up solvent. Again, like in Figure $8 \mathrm{a}, n-\mathrm{C}_{18}$ is not taken into account for alpha(Paraffin) determination.

Apart from these experimental anomalies, it has to be noticed the special behaviour of methane and ethylene (see Fig. $8 b$ ). It is well know that methane does not belong to the ASF plot and this is usually explained by the methanation 
side-reaction which is independent of the polymerisation Fischer-Tropsch process. But, we can observed that ethane belongs to the ASF Paraffin linear plot; so, ethane is included in the data used for alpha(Paraffin) determination (range $\mathrm{C}_{2}-\mathrm{C}_{84}$ taken into account). However, it is not the case for ethylene which presents a "negative" deviation towards the ASF Olefin linear plot. Among olefin products, ethylene is the first or initial product of the chain growth process. Ethylene is known to be very reactive versus re-insertion and that can be the reason of its negative deviation. Finally, concerning oxygenates products, it cannot be excluded that methanol present also a special behaviour and do not belong to oxygenates' ASF distribution. However, it is not so appreciable as methane and ethylene. Thus, also taking into account its low contribution among whole products distribution, it has been kept included for the alpha oxygenates determination (see Fig. 8b).

\subsection{Discussion and Mechanism Hypothesis}

Now, taking into account these new experimental results, we can discuss their significance. These results are not enough to build a new reaction mechanism, further work is needed. However, they bring new information which should let improve the reaction present knowledge. Based on complementary experiments (not reported here and which will be further published), preliminary ideas are proposed here. A basic interpretation would be to consider three different catalytic sites, which would develop independently the chain growth for respectively paraffin, olefin and oxygenates products. However, this would not be coherent with former results reported [4]. Actually, our preferred hypothesis to explain these results and the obtaining of three various chain growth factors according to each hydrocarbons family formed, respectively paraffin, olefin and oxygenates (i.e. alcohols as primary products) remains based on a single (or same) type of catalytic site which can develop the chain growth process. However, our proposal takes into consideration the peculiar specificity of each catalytic sites: one of our ideas is that, according to catalytic sites environment, in particular concentration and nature of adsorbed species present nearby primary alkyl chain, the chain growth would lead always versus the same type of products (paraffin, olefin or alcohol). And this would results in a proper and distinguished chain growth factor for each type of hydrocarbon products. Of course, the Fischer-Tropsch reaction conditions such as temperature, pressure or $\mathrm{H}_{2} / \mathrm{CO}$ feed ratio could modify the catalytic sites environment and result in selectivity change. For instance, an increase of hydrogen excess in the syngas feed should increase in the whole paraffin proportion (and decrease olefin proportion) due to an increase of hydrogen adsorbed species nearby the catalytic site. We can imagine that such an atmosphere modification would transform a part of "olefin catalytic sites" to "paraffin catalytic sites" because of a statistically increase of hydrogen adsorbed species at proximity of catalytic sites. According to this hypothesis, the catalyst selectivity would remains the results of catalyst characteristic and reaction conditions specificity.

\subsection{Selectivity Simulation}

Based on our experimental results, catalyst selectivity can be characterized by three chain growth coefficients in addition to olefin and oxygenates weight fraction, completed with methane and ethylene own selectivity. So, the whole FischerTropsch products distribution can be predicted from the following data set:

- the three chain growth coefficients: $\alpha_{\text {paraffin }}, \alpha_{\text {olefin }}, \alpha_{\text {oxygenates}}$,

- olefin and oxygenate weight fraction,

- Methane selectivity (wt $\%$ ),

- Ethylene selectivity (wt\%) (or C2\%*),

$-\mathrm{CO}_{2}\left(\mathrm{wt} \%{ }^{* *}\right)$.

* Ethylene selectivity can also be described from ethane weight fraction, available from the paraffin weight fraction and the alpha (Paraffin) chain growth coefficient.

** $\mathrm{CO}_{2}$ by-products obtained through Water Gas Shift side reaction can also be taken into consideration for more accurate prediction when complete carbon yield is considered. Although $\mathrm{CO}_{2}$ formation is quite limited in cobalt Fischer-Tropsch synthesis, it must be included for process integration at industrial scale.

When the impact of reaction conditions on the various parameters of the selectivity data set is known, the catalyst selectivity can be easily simulated and the whole products process yield can be predicted. By integration of whole selectivity data set, a complete kinetic model, predicting both activity and selectivity performances, is now available. In this present study, performed with an alumina supported cobalt catalyst, and in the conditions selected to carry on the Fischer-Tropsch reaction $\left(230^{\circ} \mathrm{C}, 20 \mathrm{bar}, \mathrm{H}_{2} / \mathrm{CO} 2.0, \mathrm{CO}\right.$ conversion level $56 \%$, etc.) the selectivity parameters obtained are summarized in Table 5.

TABLE 5

Selectivity data set

\begin{tabular}{l|c|c}
\hline & & Alpha validity range \\
\hline Alpha (Paraffin) & 0.91 & $\mathrm{C} 2+$ \\
\hline Alpha (Olefin) & 0.74 & $\mathrm{C} 3+$ \\
\hline Alpha (Oxygenates) & 0.85 & $\mathrm{C} 1+$ \\
\hline $\mathrm{CH}_{4}\left(\mathrm{wt} \%, \mathrm{CO}_{2}\right.$ excluded) & 8.2 & \\
\hline $\mathrm{C}_{2} \mathrm{H}_{4}\left(\mathrm{wt} \%, \mathrm{CO}_{2}\right.$ excluded) & 0.1 & \\
\hline Olefin weight fraction (wt $\%)$ & 12.1 & \\
\hline Oxygenates weight fraction (wt $\%)$ & 2.7 & \\
\hline
\end{tabular}




\section{CONCLUSION}

New analytical approaches combining different types of gas chromatography techniques deeply improve the molecular characterization of the whole FT products formed. In particular, a detailed composition of olefin and oxygenates by-products is possible thanks to magnified resolution associated with the high peak capacity provided by GC $\times$ GC. Such a detailed description of the whole FT products distribution brings additional information which can be used to improve the Fischer-Tropsch reaction knowledge such as kinetic scheme or reaction mechanism.

Thus, we have shown that all the three products family (paraffin, olefin and oxygenates) present their own ASF distribution. Apart from methane and ethylene which present their own particularity, the Fischer-Tropsch selectivity can be described by three chain growth coefficients relative to each products family and this is new compared to reaction present knowledge. These results should allow a better understanding of the reaction mechanism. Our hypothesis to explain these new results take into consideration the specificity of each catalytic sites, in particular its adsorbed species environment.

\section{REFERENCES}

1 Liu Y., Patzlaff J., Gaube J. (2004) The selectivity of FischerTropsch-Synthesis on Iron and Cobalt Catalysts - a comparison, Prepr. Pap. Am. Chem. Soc., Div. Pet. Chem. 49, 2, 165-168.

2 Schulz H., Claeys M. (1999) Kinetic modelling of FischerTropsch product distributions, Appl. Catal. 186, 91-107.

3 Schulz H., Claeys M. (1999) Reactions of alpha-olefins of different chain length added during Fischer-Tropsch synthesis on a cobalt catalyst in a slurry reactor, Appl. Catal. 186, 71-90.

4 Iglesia E. (1997) Design, synthesis, and use of cobalt-based Fischer-Tropsch synthesis catalysts, Appl. Catal. 161, 59-78.

5 Hurlbut R.S., Puskas I., Schumacher D.J. (1996) Fine details on the selectivity and kinetics of the Fischer-Tropsch synthesis over cobalt catalysts by combination of quantitative gas chromatography and modeling, Energ. Fuel. 10, 537-545.

6 Puskas I., Hurlbut R.S. (2003) Comments about the causes of deviations from the Anderson-Schulz-Flory distribution of the Fischer-Tropsch reaction products, Catal. Today 84, 99-109.

7 Patent US 6.512.017 B1.
8 Patent FR 2.870.544 B.

9 Giddings J.C. (1995) Sample dimensionality: a predictor of order-disorder in component peak distribution in multidimensional separation, J. Chromatogr. A 703, 3-15.

10 Blomberg J., Schoenmakers P.J., Brinkman U.A.Th. (2002) Gas chromatographic methods for oil analysis, J. Chromatogr. A 972, 137-173.

11 Dallüge J., Beens J., Brinkman U.A.Th. (2003) Comprehensive two-dimensional gas chromatography: a powerful and versatile analytical tool, J. Chromatogr. A. 1000, 69-108.

12 Vendeuvre C., Ruiz-Guerrero R., Bertoncini F., Duval L., Thiébaut D. (2007) Comprehensive two-dimensional gas chromatography for detailed characterisation of petroleum products, Oil Gas Sci. Technol. 62, 43-55.

13 Vendeuvre C., Ruiz-Guerrero R., Bertoncini F., Duval L., Thiébaut D, Hennion M.C. (2005) Characterisation of middledistillates by comprehensive two-dimensional gas chromatography $(\mathrm{GC} \times \mathrm{GC})$ : A powerful alternative for performing various standard analysis of middle-distillates, J. Chromatogr. A 1086, 21-28.

14 Ruiz-Guerrero R., Vendeuvre C., Bertoncini F., Thiébaut D., Espinat D. (2006) Comparison of two-dimensional gas chromatography coupled with sulphur- chemiluminescence detector to standard Methods for Speciation of sulphur-containing Compounds in middle distillates, J. Chromatogr. Sci. 44, 566574.

15 Vendeuvre C., Bertoncini F., Duval L., Duplan J.-L., Thiébaut D., Hennion M.-C. (2004) Comparison of conventional gas chromatography and comprehensive two-dimensional gas chromatography for the detailed analysis of petrochemical sample, $J$. Chromatogr. A 1056, 155-162.

16 Van der Westhuizen R., Crouch A., Sandra P. (2008) The use of $\mathrm{GC} \times \mathrm{GC}$ with time-of-flight mass spectrometry to investigate dienes and Diels-Alder polymerisation products in high-temperature Fischer-Tropsch-based fuels, J. Sep. Sci. 31, 3423-3428.

17 Schulz H., Nie Z., Ousmanov F. (2002) Construction of the Fischer-Tropsch regime with cobalt catalyst, Catal. Today $\mathbf{7 1}$, 351-360.

18 Schulz H. (2005) Comparing Fischer-Tropsch synthesis on iron and cobalt catalysts, Prepr. Pap. Am. Chem. Soc., Div. Pet. Chem. 50, 2, 155-157.

19 Schanke D., Lian P., Eri S., Rytter E., Helgeland Sannæs B., Kinnari K.J. (2001) Optimisation of Fischer-Tropsch Reactor Design and Operation in GTL Plants, Stud. Surf. Sci. Catal. 136, 239-240.

Final manuscript received in December 2008 Published online in March 2009 